Turkish Journal of Chemistry

http://journals.tubitak.gov.tr/chem/
Turk J Chem

(2022) 46: 311-319

(c) TÜBİTAK

doi:10.3906/kim-2106-49

\title{
Effect of poly(ethylene-vinyl acetate) pour point depressant on the cold flow properties and crystallization behavior of soybean biodiesel blends fuel
}

\author{
Jinbao LIU (D), Chunhua WANG (D), Qian LIU (D), Fen ZHANG (D), Xiaojie LIU (D), Min SUN*(D) \\ School of Health and Social Care, Shanghai Urban Construction Vocational College, Shanghai, China
}

Received: $19.06 .2021 \quad \bullet \quad$ Accepted/Published Online: $23.09 .2021 \quad \bullet \quad$ Final Version: 27.04 .2022

\begin{abstract}
Although biodiesel-diesel blends are being widely used in diesel engines, investigations on its cold flow properties and crystallization behavior are still scarce. In this paper, poly(ethylene-vinyl acetate) (PEVA) pour point depressant and petroleum diesel were worked together to enhance the cold flow properties of soybean biodiesel. PEVA presented a better positive effect in reducing the cold filter plugging point (CFPP) of biodiesel blends. B40 treated with 1\% PEVA exerted the best cold flow properties, and its CFPP was decreased by $-14{ }^{\circ} \mathrm{C}$. In addition, the crystallization behavior was changed variously. The sizes of crystals were decreased as well as the number of crystals was increased notably.
\end{abstract}

Key words: Soybean biodiesel, biodiesel-diesel blends, poly(ethylene-vinyl acetate), cold filter plugging point, crystallization behavior

\section{Introduction}

Along with social and economic speediness development, the need for petroleum diesel fuels increases day by day. Biodiesel is an alternative diesel fuel derived from vegetable oils, animal fats, and other lipids [1,2]. Interest in developing biodiesel as an alternative fuel has grown in recent years because of its renewability and environmental benefits $[3,4]$.

Nevertheless, biodiesel is always limited by its poor low-temperature flow characteristics. The crystallization of biodiesel components at relatively high temperatures during cold seasons causes fuel starvation and operability problems because solidified materials clog fuel lines and filters [5,6]. Several approaches can be used to solve this issue [7-13], such as adding pour point depressants (PPDs), blending with petro-diesel, branched-chain esters, and winterization. Adding PPDs is highly practical, but the available types of biodiesel PPDs are insufficient, the effects are not ideal and the supply cannot meet the demand. Using biodiesel mixed with petroleum diesel and then adding a PPD can greatly enhance its lowtemperature flowability. Many studies [14-16] have investigated biodiesel blends. Xue et al. [17] have studied the effect of poly-alpha-olefin (PAO) on the cold flow properties of waste cooking oil biodiesel-diesel blends. PAO has proved to be an effective cold flow improver for waste cooking oil biodiesel blends; and it is more sensitive to B20 ( 20 vol.\% biodiesel+80 vol.\% diesel) than to others blends. B20 treated with $400 \mathrm{ppm}$ PAO exhibited the best depression in cold filter plugging point (CFPP) by $9{ }^{\circ} \mathrm{C}$. Ma et al.[18] have added the methacrylate PPD (10-320) into the soybean biodiesel blends to improve the cold flow properties. The constant addition of PPDs resulted in minimal values of CFPP as the proportion of biodiesel varied from 0 vol.\% to 100 vol.\%. B60 (60 vol.\% biodiesel+40 vol.\% diesel) with 1\% 10-320 PPD produced the most significant reduction in biodiesel blends, and the CFPP reduced by $7{ }^{\circ} \mathrm{C}$. Also, the dispersants were combined with the methacrylate-benzyl methacrylate-Nvinyl-2- pyrrolidone terpolymers (RMC-MB-NVP, $\mathrm{R}=\mathrm{C}_{12}, \mathrm{C}_{14}, \mathrm{C}_{16}, \mathrm{C}_{18}$ ) to improve the cold flow properties of waste cooking oil biodiesel blends [19]. Among them, $\mathrm{C}_{16} \mathrm{MC}-\mathrm{MB}-\mathrm{NVP}$ (5:1:1) combined with the dispersant of fatty alcohol polyoxyethylene ether (FAPE 7) at 4:1 mass ratio showed the best synergistic effect, and the CFPP of B20 decreased by $10{ }^{\circ} \mathrm{C}$ at $2000 \mathrm{ppm}$. However, given that biodiesel compositions vary with the source and the unsatisfying and low depressive effect on the CFPP, studies on the mechanism of PPD-supplemented biodiesel at low temperatures are required because this mechanism remains unclear.

The present work used poly(ethylene-vinyl acetate) (PEVA) as an effective PPD for biodiesel and petroleum diesel blends to investigate the impacts on cold flow properties of soybean biodiesel blends. Differential scanning calorimetry (DSC), polarizing optical microscopy (POM), and low temperature X-ray diffraction (XRD) were used to investigate the performance mechanism of PEVA-supplemented biodiesel to further develop new biodiesel PPDs.

*Correspondence: 13636680176@163.com 


\section{Experimental}

\subsection{Materials}

Diesel fuel untreated with any other PPDs was obtained from Sinopec Group, Shanghai, China. PEVA pour-point depressant was obtained from Rohmax Corporation, Germany. Soybean oil was obtained from a supermarket (Shanghai, China), and the soybean oil biodiesel (SBD) was prepared in our laboratory by transesterification method according to previous literature [17].

\subsection{Biodiesel compositions measurements}

Agilent 7890A-5975c gas chromatography-mass spectrometer (GC-MS) was used to analyze the biodiesel composition [18]. The GC operation conditions were as follows: HP-Innowax quartz capillary column $(60 \mathrm{~m} \times 0.25 \mathrm{~mm} \times 0.25 \mu \mathrm{m})$; capillary-column temperature initially raised by $10{ }^{\circ} \mathrm{C} / \mathrm{min}$ from $60^{\circ} \mathrm{C}$ to $150{ }^{\circ} \mathrm{C}$, and then raised by $5{ }^{\circ} \mathrm{C} / \mathrm{min}$ from 150 ${ }^{\circ} \mathrm{C}$ to $230^{\circ} \mathrm{C}$; interface temperature of $250^{\circ} \mathrm{C}$; injector temperature of $250^{\circ} \mathrm{C}$; diffluent ratio of $100: 1$; high-purity helium carrier gas with a flow rate of $1 \mathrm{~mL} / \mathrm{min}$; and injection volume of $0.2 \mu \mathrm{L}$. The compositions of the prepared SBD are listed in Table 1.

\subsection{CFPP measurements}

CFPP corresponds to the temperature where wax crystals have agglomerated in sufficient quantity to cause a diesel fuel filter to plug. At present, CFPP is normally used locally to evaluate the cold flow property of diesel. It was determined using a SYP1022-2 multifunctional low-temperature tester (Shanghai Boli Instrument Co., Ltd.) according to ASTM D6371 standard [20]. In addition, other fuel properties, such as cloud point, pour point, flash point, oxidation stability, kinematic viscosity, and acid value, were also determined, and the fuel properties of the diesel and SBD used in this work are shown in Table 2.

\subsection{Crystal morphology and crystallization behavior measurements}

A DSC27HP differential scanning calorimeter (Mettler Corporation, Switzerland) was used to determine the wax precipitation point. The operating conditions are as follows: $8-10 \mathrm{mg}$ samples were put in standard crucibles. Transition

Table 1. The compositions of SBD.

\begin{tabular}{|l|l|l|}
\hline Name of fatty acid methyl esters (FAMEs) & Corresponding acid & Mass percent (wt.\%) \\
\hline Methyl hexadecanoate & $16: 0$ & 11.26 \\
\hline Methyl octadecanoate & $18: 0$ & 5.34 \\
\hline Methyl oleate & $18: 1$ & 25.19 \\
\hline Linoleic acid methyl ester & $18: 2$ & 47.58 \\
\hline Linolenic acid methyl ester & $18: 3$ & 9.13 \\
\hline Methyl eicosanoate & $20: 0$ & 0.77 \\
\hline Total saturated FAMEs & & 17.37 \\
\hline Total unsaturated FAMEs & & 81.90 \\
\hline
\end{tabular}

Note: (16:0) indicates that FAME has 16 of carbons and 0 of unsaturated bonds in the corresponding acid.

Table 2. The fuel properties of pure SBD (B100) and pure diesel (B0).

\begin{tabular}{|l|l|l|l|l|}
\hline Properties & Test methods & ASTM D6751 & SBD & Diesel \\
\hline Cloud point, ${ }^{\circ} \mathrm{C}$ & ASTM D2500 & Report & -1 & 2 \\
\hline Pour point, ${ }^{\circ} \mathrm{C}$ & ASTM D97 & - & -5 & -4 \\
\hline Cold filter plugging point, ${ }^{\circ} \mathrm{C}$ & ASTM D6371 & - & -2 & 1 \\
\hline Flash point, ${ }^{\circ} \mathrm{C}$ & ASTM D93 & $130 \mathrm{~min}$ & 143 & 69 \\
\hline Oxidation stability, $110^{\circ} \mathrm{C}, \mathrm{h}$ & EN14214 & 3 min & 5.2 & 7.8 \\
\hline Kinematic viscosity, $40^{\circ} \mathrm{C}, \mathrm{mm}_{2} / \mathrm{s}$ & ASTM D445 & $1.9-6.0$ & 4.10 & 2.47 \\
\hline Acid value, $\mathrm{mg} \mathrm{KOH} / \mathrm{g}$ & ASTM D664 & $0.50 \mathrm{max}$ & 0.38 & 0.13 \\
\hline
\end{tabular}


temperatures and enthalpies were determined using a computer during the heating cycle at a scanning rate of $5{ }^{\circ} \mathrm{C} / \mathrm{min}$ and a range of $30^{\circ} \mathrm{C}-60^{\circ} \mathrm{C}$.

A DM2500P polarizing optical microscope (Leica Microsystems, Wetzlar, Germany) equipped with a Leica DFC420C digital camera was used to determine the low-temperature phase/crystallization behavior of diesel fuel. A sample was dropped onto a slide and then observed at a cooling rate of $0.8{ }^{\circ} \mathrm{C} / \mathrm{min}$ from $20^{\circ} \mathrm{C}$ to $-30^{\circ} \mathrm{C}$, and the micrographs were captured in $1^{\circ} \mathrm{C}$ increment under a magnification of $100 \times[21]$.

X'Pert PRD XRD system (PANalytical Corporation, Netherlands) was used to determine the lattice parameter and structure of wax crystals under the following operating conditions: tube voltage of $40 \mathrm{kV}$, tube current of $40 \mathrm{~mA}$, graphite monochromator, and $\mathrm{Cu} \mathrm{Ka}$ radiation $(\lambda=1.542 \AA)$ [22].

\section{Results and discussion}

\subsection{Composition and fuel properties of SBD}

The compositions and fuel properties of SBD are shown in Table 1 and Table 2. As shown in Table 1 and Table 2, SBD consists of various FAMEs with different carbon chains and saturated compositions, and the content of unsaturated FAMEs is $81.88 \%$ higher than saturated FAMEs (17.41\%). All fuel properties of the prepared SBD satisfied the ASTM D6751 standards. However, due to the relatively higher contents and freezing point of saturated FAMEs, the biodiesel and its blends with petro-diesel used in a diesel engine in cold climates were always limited by their weaker cold flow properties.

\subsection{Impact of PEVA on soybean biodiesel blends}

The effect of various dosages of PEVA on the CFPP of soybean biodiesel blends is shown in Figure 1.

As it can be seen from Figure 1, the CFPP of biodiesel blends without PEVA was stable between $0{ }^{\circ} \mathrm{C}$ and $-2{ }^{\circ} \mathrm{C}$, dosing different PEVA into various biodiesel blends present distinct-different depression effects. PEVA had essentially slight or reactive effects on the CFPP of $\mathrm{B} 100$ (pure biodiesel), and the CFPP of $\mathrm{B} 100$ was increased from $-2{ }^{\circ} \mathrm{C}$ to $0{ }^{\circ} \mathrm{C}$ after treated with 1\% PEVA, indicating that the sensitivity of PEVA to pure SBD was poor. After the biodiesel blends were treated with PEVA, the reduction of CFPP increased firstly and it remained almost unchanged or slightly decreased as the dosage of PEVA above $1 \mathrm{wt} . \%$. The CFPP of B0 (pure diesel), B20 (20vol.\% biodiesel + 80vol.\% diesel), and B40 (40vol.\% biodiesel + $60 \mathrm{vol} . \%$ diesel) decreased obviously with the PEVA increased from $0.4 \mathrm{wt} . \%$ to $1.2 \mathrm{wt} . \%$ than that of B60 (60vol.\% biodiesel $+40 \mathrm{vol} . \%$ diesel), B80 (80vol.\% biodiesel + 20vol.\% diesel) and B100, and adding 1\% PEVA produced the lowest CFPP. Meanwhile, the effects of PEVA on B20 and B40 were similar to those on B0. B0 treated with 1 wt.\% PEVA exhibited a relatively low CFPP of $-13{ }^{\circ} \mathrm{C}$, while adding $1 \mathrm{wt} . \%$ PEVA to $\mathrm{B} 20$ and $\mathrm{B} 40$ produced the lowest CFPP at $-14{ }^{\circ} \mathrm{C}$. It indicates that 1wt.\% PEVA exhibited a better sensitivity to the biodiesel-diesel blends with a low percentage of biodiesel (B40 and B20). Therefore, given its environmental friendliness and to make full use of more biodiesel, formulated B40 with 1wt.\% was considered to be the ideal biodiesel blends with the best cold flow properties.

\subsection{DSC analysis}

DSC can quantitatively analyze energetic changes in the phase-change process in biodiesel blends with PEVA. The starting temperature of peak (onset) in a curve reflects the starting temperature of precipitation of crystals, the slope of peak reflects

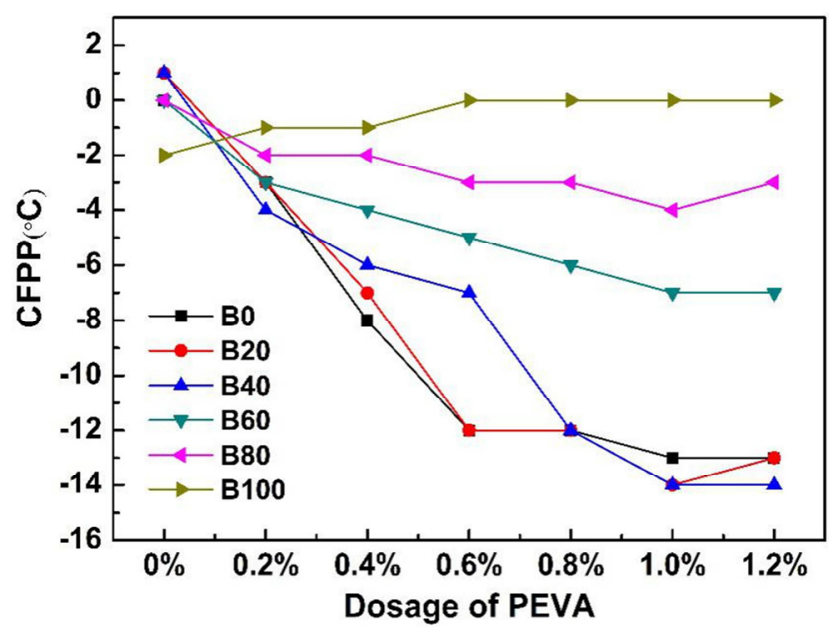

Figure 1. Effect of PEVA on the CFPP of soybean biodiesel blends. 
the rate of precipitation in diesel, and the solid-liquid phase-change energy $(\Delta \mathrm{H})$ reflects the stability of the dispersion. The DSC curves and analyses of B0, B40, and B100 with 1\% PEVA are shown in Figure 2 and Table 3, respectively.

Table 3 shows that the onset of the peak of $\mathrm{B} 40$ was $-12.05^{\circ} \mathrm{C}$ between $\mathrm{B} 0\left(-11.67^{\circ} \mathrm{C}\right)$ and $\mathrm{B} 100\left(-3.98^{\circ} \mathrm{C}\right)$. Two crystals precipitated at a low temperature, and peak temperature was consistent with that of onset temperature, indicating the time of three samples from onset to the peak were not very different. The absolute value of $\Delta \mathrm{H}$ of B40 was the smallest $\left(0.4320 \mathrm{~J} \mathrm{~g}^{-1}\right)$, indicating that the solid-liquid phase-change energy of biodiesel blends was smaller and dispersion was more stable. The crystallization-peak area of B40 was the smallest (3.348), indicating that crystal content was the least. The crystallization-peak slope further revealed that the crystallization rate of B100 was fast, the crystallization rate of B0 was slow, and the crystallization rate of B40 was the slowest. Thus, the CFPP of PEVA-supplemented B40 was lower than that of other biodiesel blends.

\subsection{POM analysis}

POM has proven to be an effective method that can be used to observe changes in wax crystals in the biodiesel blends with and without PEVA [23,24]. The crystal morphology and crystallization behavior of untreated and $1 \%$ PEVA treated B0, B40, and $\mathrm{B} 100$ were observed by POM at $-5^{\circ} \mathrm{C}$ and $-15^{\circ} \mathrm{C}$, and are shown in Figure 3 .

Figure 3 shows dense net-like wax crystals in B100 (Figure $3 \mathrm{a}_{1}$ ), needle-like wax crystals in B0 (Figure $3 \mathrm{~b}_{1}$ ), and grain shaped crystals in smaller sizes at $-5^{\circ} \mathrm{C}$ (Figure $3 c_{1}$ ). In the presence of PEVA, the crystallization behavior was changed variously. The sizes of crystals were decreased as well as the number of crystals was increased notably (Figure $3 \mathrm{~d}_{1} e_{1}$ and $\mathrm{f}_{1}$ ). The crystals in treated B100 became more regular but intensive-huddled, resulting in the deviation of CFPP (Figure $3 \mathrm{~d}_{1}$ ). The shapes of crystals in treated B0 (Figure $3 \mathbf{e}_{1}$ ) and B40 (Figure $3 \mathrm{f}_{1}$ ) changed from needle- and grain-like to fine granules, whereas the size of crystals in treated B40 was far less and the quantity was much more than those in treated B0. Following the temperature drops to $-15{ }^{\circ} \mathrm{C}$, larger and more crystals were appeared and aggregated in three-dimensional network structures in both untreated and treated B100, B0, and B40, thus losing their flowability at low temperature (Figure $3 \mathrm{a}_{2 \sim} \mathrm{f}_{2}$ ). However, two kinds of crystals from biodiesel and diesel precipitated together at low temperatures, one crystal scattered around another crystal and produced some exclusion, thereby inhibiting formation and growth of large and stripe-like crystals by cocrystallization (Figure $3 \mathrm{f}_{1}$ and $\mathrm{f}_{2}$ ). Ultimately, the PEVA treated B40 presented a lower CFPP.

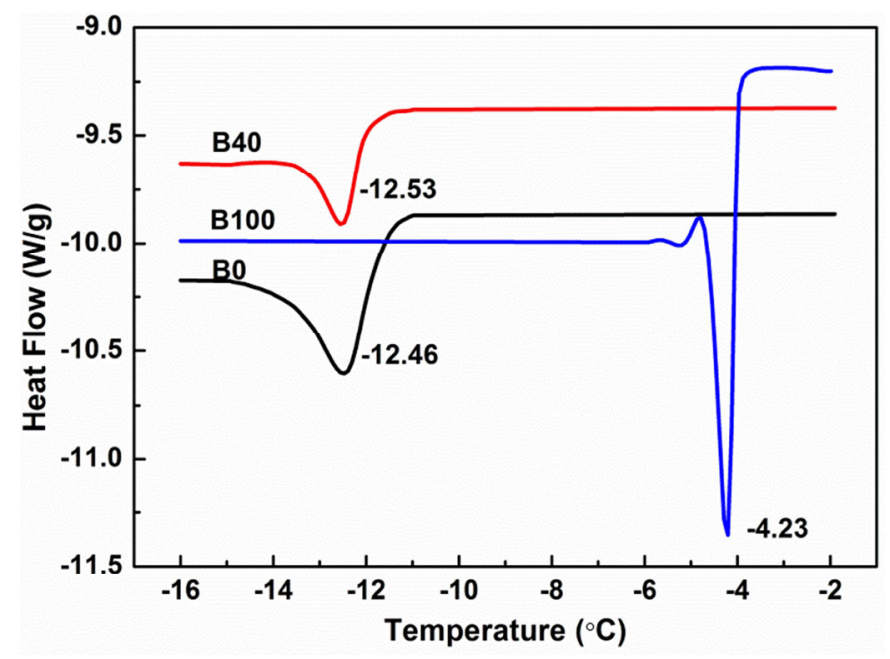

Figure 2. DSC curves of B0, B40, and B100 with 1wt.\% PEVA.

Table 3. Analysis of DSC of B0, B40, and B100 with 1wt.\% PEVA.

\begin{tabular}{|l|l|l|l|l|}
\hline Sample & Onset $/{ }^{\circ} \mathrm{C}$ & Peak $/{ }^{\circ} \mathrm{C}$ & $\Delta \mathrm{H} / \mathrm{J} \cdot \mathrm{g}^{-1}$ & Area \\
\hline B0 & -11.67 & -12.46 & -1.1491 & 10.365 \\
\hline B40 & -12.05 & -12.53 & -0.4320 & 3.348 \\
\hline B100 & -3.98 & -4.23 & -1.0485 & 8.531 \\
\hline
\end{tabular}



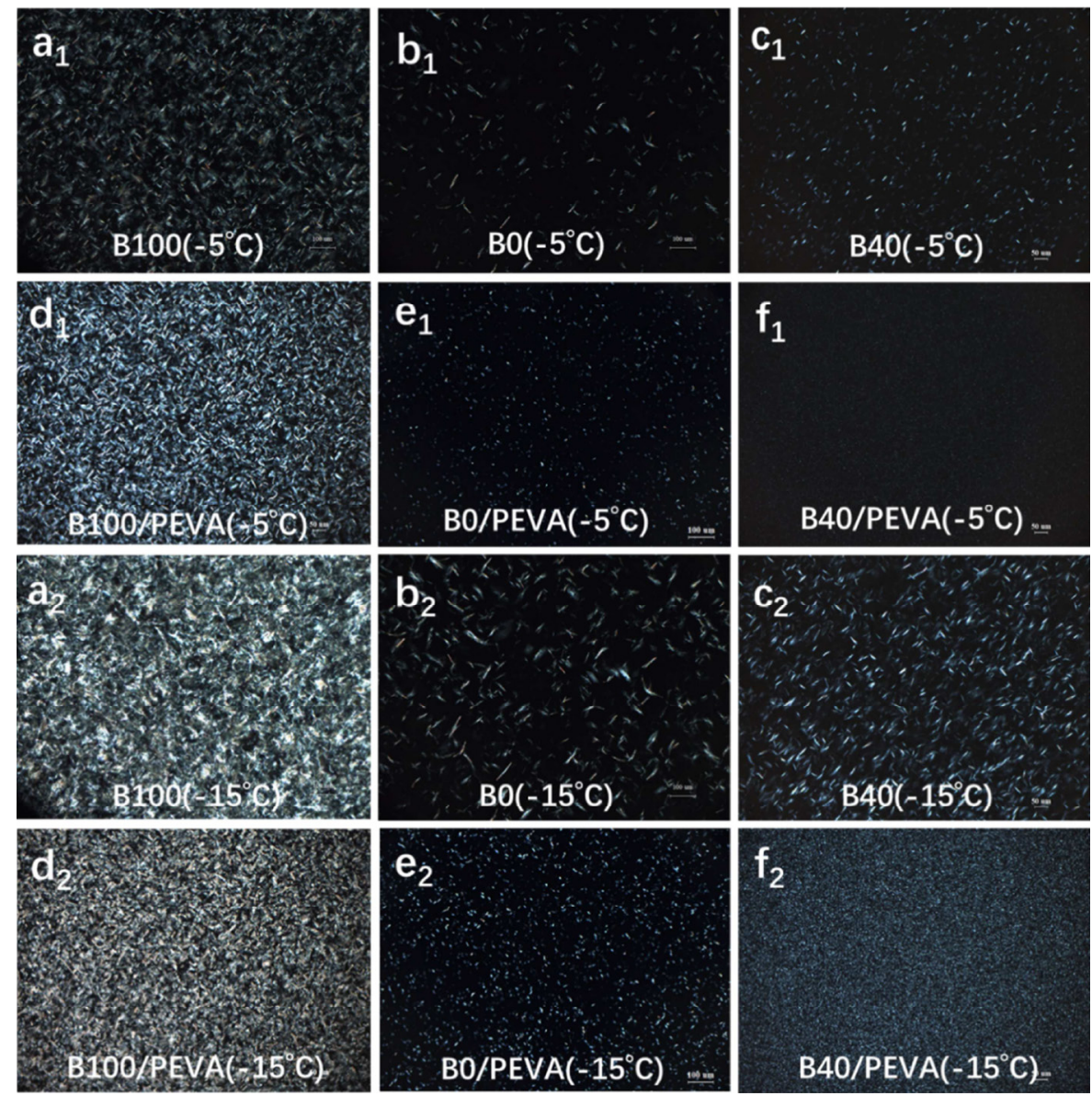

Figure 3. POM images of crystal morphologies of B100( $\mathbf{a}_{1}$ and $\left.\mathbf{a}_{2}\right), \mathrm{B} 0\left(\mathbf{b}_{1}\right.$ and $\left.\mathbf{b}_{2}\right)$, and B40( $\mathbf{c}_{1}$

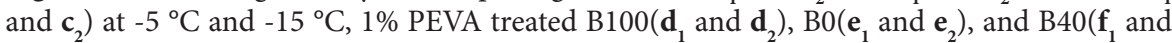
$\mathbf{f}_{2}$ ) at $-5^{\circ} \mathrm{C}$ and $-15^{\circ} \mathrm{C}$.

\subsection{XRD analysis}

Low-temperature XRD can be used to analyze the lattice parameters and structure of wax crystals in biodiesel [25]. The low-temperature XRD of $1 \%$ PEVA treated B0, B40, and B100 at $-10{ }^{\circ} \mathrm{C}$ are shown in Figure 4.

As it can be seen from Figure 4, the diffusion peak at $10^{\circ}-30^{\circ}$ was quite obvious in B0/PEVA and B100/PEVA. Sharp orthorhombic diffraction peaks were observed at $21.5^{\circ}$ and $23.8^{\circ}$, and sharp monoclinic diffraction peaks were observed at $41.3^{\circ}, 42.9^{\circ}, 44.0^{\circ}, 46.2^{\circ}, 50.0^{\circ}, 51.3^{\circ}$, and $52.3^{\circ}$, indicating that amorphous and crystalline wax precipitated at low temperatures. The broad of diffusion peaks of B0/PEVA was the first, next was that of B100/PEVA followed by B40/PEVA, so the content of amorphous-wax crystals in pure diesel was more than that in pure biodiesel.

As shown in Table 4 and Table 5, the crystallization-peak areas of three diesels were in the order B0 (136082) > B100 $(100045)>B 40$ (85001), indicating that crystal content in treated B40 decreased at the same temperature. The ratio of orthorhombic to monoclinic peak area in B40/PEVA was 0.14, which is lower than that of 0.15 in B0/PEVA and 0.43 in B100/PEVA. In Table 5, $\boldsymbol{A}_{\boldsymbol{0}}$ refers to the total area of crystallization peak $\left(10.0^{\circ}-60.0^{\circ}\right), \boldsymbol{A}_{1}$ refers to the total area of sharp monoclinic diffraction peaks ranges from $40.0^{\circ}$ to $60.0^{\circ}$, and $S$ refers to the relative area of orthorhombic area to monoclinic area. This finding indicates that PEVA changed the ratio of two types of crystals by cocrystallization. For another, the ratio of monoclinic peak area $\left(\mathrm{A}_{1}\right)$ to $\mathrm{A}_{0}$ in B40/PEVA (0.87) was higher than that of B0/PEVA (0.86) B100/ PEVA (0.69). As the aggregation and growth of monoclinic crystals are known to be difficult the crystal size in the PEVA treated B40 was smaller and more easily passed through the filter, resulting in a lower CFPP.

3.6. Effect of PEVA on the fuel properties of biodiesel blends

In summary, B40 treated with 1\% PEVA presents the best cold flow properties. Table 6 shows the fuel properties of B40, and 1\% PEVA treated B40. As it can be seen from Table 6 and Table 2, the fuel properties of B40 are different from that 


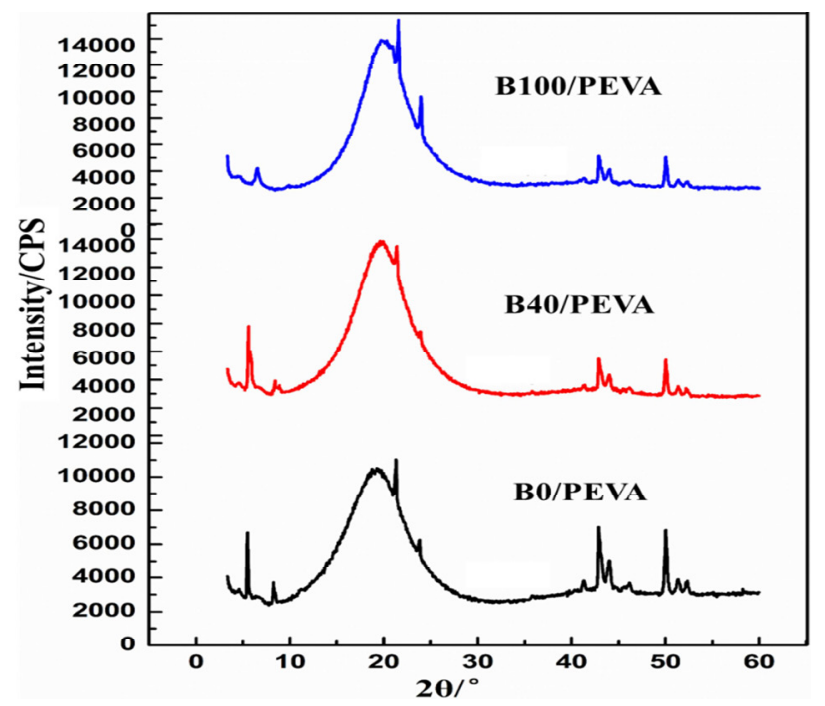

Figure 4. Low-temperature XRD curves of 1 wt.\% PEVA treated B0, B40, and B100 at $-10^{\circ} \mathrm{C}$.

Table 4. Analysis of XRD of 1wt.\% PEVA treated B0, B40, and B100.

\begin{tabular}{|c|c|c|c|c|}
\hline Sample & 2-Theta & $\mathrm{d}(\mathrm{A})$ & Height & Area \\
\hline \multirow{9}{*}{ B0/PEVA } & 21.313 & 4.1655 & 2241 & 14,308 \\
\hline & 23.791 & 3.7368 & 778 & 3967 \\
\hline & 41.279 & 2.1853 & 596 & 5883 \\
\hline & 42.93 & 2.105 & 3086 & 33,243 \\
\hline & 44.017 & 2.0555 & 1403 & 15,799 \\
\hline & 46.164 & 1.9648 & 508 & 9424 \\
\hline & 50.025 & 1.8218 & 3641 & 37,361 \\
\hline & 51.343 & 1.7781 & 741 & 8985 \\
\hline & 52.301 & 1.7477 & 607 & 7112 \\
\hline \multirow{9}{*}{ B40/PEVA } & 21.383 & 4.1519 & 1694 & 9482 \\
\hline & 23.822 & 3.7321 & 173 & 1406 \\
\hline & 41.313 & 2.1835 & 327 & 4029 \\
\hline & 42.931 & 2.1049 & 1828 & 20,020 \\
\hline & 43.987 & 2.0568 & 831 & 9477 \\
\hline & 46.164 & 1.9648 & 327 & 6595 \\
\hline & 50.025 & 1.8218 & 2341 & 23,875 \\
\hline & 51.346 & 1.778 & 522 & 5883 \\
\hline & 52.267 & 1.7488 & 382 & 4234 \\
\hline \multirow{9}{*}{ B40/PEVA } & 21.575 & 4.1155 & 3185 & 17106 \\
\hline & 23.985 & 23.985 & 2397 & 13,069 \\
\hline & 41.311 & 41.311 & 347 & 6006 \\
\hline & 42.96 & 42.96 & 1693 & 18,053 \\
\hline & 43.987 & 43.987 & 795 & 8916 \\
\hline & 46.195 & 46.195 & 264 & 5969 \\
\hline & 50.026 & 50.026 & 2122 & 21,385 \\
\hline & 51.345 & 51.345 & 445 & 5707 \\
\hline & 52.333 & 52.333 & 334 & 3834 \\
\hline
\end{tabular}


LIU et al. / Turk J Chem

Table 5. Analysis of XRD of 1wt.\% PEVA treated B0, B40, and B100.

\begin{tabular}{|c|c|c|c|c|c|c|c|c|}
\hline \multicolumn{3}{|c|}{ B0/PEVA } & \multicolumn{3}{|c|}{ B40/PEVA } & \multicolumn{3}{|c|}{ B100/PEVA } \\
\hline S & $\mathrm{A}_{0}$ & $\mathrm{~A}_{1}$ & $S$ & $\mathrm{~A}_{0}$ & $\mathrm{~A}_{1}$ & $S$ & $\mathrm{~A}_{0}$ & $\mathrm{~A}_{1}$ \\
\hline 0.15 & 136,082 & 117,807 & 0.14 & 85,001 & 74,113 & 0.43 & 100,045 & 68,870 \\
\hline
\end{tabular}

Table 6. The fuel properties of B40 and 1\% PEVA treated B40.

\begin{tabular}{|l|l|l|}
\hline Properties & B40 & PEVA treated B40 \\
\hline Cloud point, ${ }^{\circ} \mathrm{C}$ & 1 & -3 \\
\hline Pour point, ${ }^{\circ} \mathrm{C}$ & -4 & -17 \\
\hline Cold filter plugging point, ${ }^{\circ} \mathrm{C}$ & 0 & -14 \\
\hline Flash point, ${ }^{\circ} \mathrm{C}$ & 117 & 119 \\
\hline Oxidation stability, $110^{\circ} \mathrm{C}, \mathrm{h}$ & 6.1 & 6.3 \\
\hline Kinematic viscosity, $40^{\circ} \mathrm{C}, \mathrm{mm} 2 / \mathrm{s}$ & 3.16 & 3.20 \\
\hline Acid value, $\mathrm{mg} \mathrm{KOH} / \mathrm{g}$ & 0.21 & 0.22 \\
\hline
\end{tabular}

of $\mathrm{B} 0$ and $\mathrm{B} 100$ due to their huge differences in compositions. After being treated with 1\% PEVA, the CFPP of PEVAsupplemented $\mathrm{B} 40$ is rand the $\mathrm{CP}$ and $\mathrm{PP}$ are reduced from $0{ }^{\circ} \mathrm{C}$ to $-14^{\circ} \mathrm{C}$, and the $\mathrm{CP}$ and $\mathrm{PP}$ are reduced from $1{ }^{\circ} \mathrm{C}$ and $-4{ }^{\circ} \mathrm{C}$ to $-3{ }^{\circ} \mathrm{C}$ and $-17^{\circ} \mathrm{C}$, respectively. For another, the presence of PEVA in $\mathrm{B} 40$ appeared to have no significant effect on other fuel properties of B40, and the flash point, oxidation stability, kinematic viscosity, acid value of B40 just occur a slight increase.

\section{Conclusions}

(1) The effects of PEVA on the cold flow properties of soybean biodiesel blends were studied; the CFPP of PEVAsupplemented B40 was lower than that of other blends. B40 treated with 1\% PEVA presents the best cold flow properties.

(2) Performance mechanisms of PEVA in soybean biodiesel blends are described as follows: PEVA in B40 effectively lowered the crystallization rate of wax crystals, changed the process of crystal growth by cocrystallization, and many small spherical wax crystals existed in B40 that inhibited the formation and growth of the larger crystal, therefore, the CFPP of PEVA-supplemented B40 was lower than that of untreated B40. The crystal size in the PEVA treated B40 was smaller and more easily passed through the filter, resulting in a lower CFPP.

$\begin{array}{ll}\text { Nomenclature } \\ \text { CFPP } & \text { cold filter plugging point } \\ \text { PPD } & \text { pour point depressant } \\ \text { PPDs } & \text { pour point depressants } \\ \text { SBD } & \text { soybean biodiesel } \\ \text { PEVA } & \text { poly(ethylene-vinyl acetate) } \\ \text { DSC } & \text { differential scanning calorimetry } \\ \text { POM } & \text { polarizing optical microscopy } \\ \text { XRD } & \text { X-ray diffraction } \\ \text { GC-MS } & \text { gas chromatography-mass spectrometer } \\ \text { FAME } & \text { fatty acid methyl ester } \\ \text { FAMEs } & \text { fatty acid methyl esters } \\ \text { B0 } & \text { pure diesel } \\ \text { B20 } & \text { 20vol.\% biodiesel + 80vol.\% diesel } \\ \text { B40 } & \text { 40vol.\% biodiesel + 60vol.\% diesel } \\ \text { B60 } & \text { 60vol.\% biodiesel + 40vol.\% diesel } \\ \text { B80 } & \text { 80vol.\% biodiesel + 20vol.\% diesel } \\ \text { B100 } & \text { pure biodiesel }\end{array}$




\section{LIU et al. / Turk J Chem}

\section{Acknowledgments}

This work was supported by the Chenguang Program of Shanghai Education Development Foundation and Shanghai Municipal Education Commission (Project Number 18CGB12).

\section{References}

1. Ambat I, Srivastava V, Sillanpää M. Recent advancement in biodiesel production methodologies using various feedstock: A review. Renewable and Sustainable Energy Reviews 2018; 90: 356-369. doi: 10.1016/j.rser.2018.03.069

2. Gebremariam SN, Marchetti JM. Economics of biodiesel production. Energy Conversion and Management 2018; 168: 74-84. doi: 10.1016/j. enconman.2018.05.002

3. Sharma A, Maurya NM, Singh Y, Singh NK, Gupta SK. Effect of design parameters on performance and emissions of DI diesel engine running on biodiesel-diesel blends: Taguchi and utility theory. Fuel 2020; 281: 118765. doi: 10.1016/j.fuel.2020.118765

4. Nasir DSNM, Pantua CAJ, Zhou B, Vital B, Calautit J et al. Numerical analysis of an urban road pavement solar collector (U-RPSC) for heat island mitigation: Impact on the urban environment. Renewable Energy 2021; 164: 521-530. doi: 10.1016/j.renene.2020.07.107

5. Chen W, Wang Y, Ding M, Shi S, Yang Z. Crystallization behaviors and rheological properties of biodiesel derived from methanol and ethanol. Fuel 2017; 207: 503-509. doi: 10.1016/j.fuel.2017.06.121

6. Knothe G, Dunn RO. A comprehensive evaluation of the melting points of fatty acids and esters determined by differential scanning calorimetry. Journal of the American Oil Chemists' Society 2009; 86 (9): 843-856. doi: 10.1007/s11746-009-1423-2

7. Vijayan SK, Victor MN, Sudharsanam A, Chinnaraj VK, Nagarajan V. Winterization studies of different vegetable oil biodiesel. Bioresource Technology Reports 2018; 1: 50-55. doi: 10.1016/j.biteb.2018.02.005

8. Liu T, Fang L, Liu X, Zhang X. Preparation of a kind of reactive pour point depressant and its action mechanism. Fuel 2015; 143: 448-454. doi: 10.1016/j.fuel.2014.11.094

9. Dunn RO, Wyatt VT, Wagner K, Ngo H, Hums ME. The effect of branched-chain fatty acid alkyl esters on the cold flow properties of biodiesel. Journal of the American Oil Chemists' Society 2019; 96: 805-823. doi: 10.1002/aocs.12226

10. Mujtaba MA, Kalam MA, Masjuki HH, Gul M, Soudagar MEM et al. Comparative study of nanoparticles and alcoholic fuel additivesbiodiesel-diesel blend for performance and emission improvements. Fuel 2020; 279: 118434. doi: 10.1016/j.fuel.2020.118434

11. Magalhaes AMS, Pereira E, Meirelles AJA, Sampaio KA, Maximo GJ. Proposing blends for improving the cold flow properties of ethylic biodiesel. Fuel 2019; 253: 50-59. doi: 10.1016/j.fuel.2019.04.129

12. Zhao Z, Yan S, Lian J, Chang W, Xue Y et al. A new kind of nanohybrid poly(tetradecyl methyl-acrylate)-graphene oxide as pour point depressant to evaluate the cold flow properties and exhaust gas emissions of diesel fuels. Fuel 2018; 216: 818-825. doi: 10.1016/j. fuel.2017.07.087

13. Xue Y, Zhao W, Ma P, Zhao ZC, Xu G et al. Ternary blends of biodiesel with petro-diesel and diesel from direct coal liquefaction for improving the cold flow properties of waste cooking oil biodiesel. Fuel 2016; 177: 46-52. doi: 10.1016/j.fuel.2016.02.087

14. Lapuerta M, Fernández JR, Rodríguez DF, Camino RP. Cold flow and filterability properties of n-butanol and ethanol blends with diesel and biodiesel fuels. Fuel 2018; 224: 552-559. doi: 10.1016/j.fuel.2018.03.083

15. Magalhães AMS, Pereira E, Meirelles AJA, Sampaio KA, Maximo GJ. Proposing blends for improving the cold flow properties of ethylic biodiesel. Fuel 2019; 253: 50-59. doi: 10.1016/j.fuel.2019.04.129

16. Echim C, Maes J, Greyt WD. Improvement of cold filter plugging point of biodiesel from alternative feedstocks. Fuel, 2012; 93: 642-648. doi: 10.1016/j.fuel.2011.11.036

17. Xue Y, Zhao Z, Xu G, Lian X, Yang C. Effect of poly-alpha-olefin pour point depressant on cold flow properties of waste cooking oil biodiesel blends. Fuel 2016; 184: 110-117. doi: 10.1016/j.fuel.2016.07.006

18. Ma P, Xue Y, Zhao W, Lan G, Hang Z et al. Study on the performance mechanism of methacrylate pour point depressant in soybean biodiesel blends. RSC Advances 2015; 5 (109): 90144-90149. doi: 10.1039/C5RA15077A

19. Su B, Wang L, Xue Y, Dong ZJ, Lin H et al. Effect of pour point depressants combined with dispersants on the cold flow properties of biodiesel-diesel blends. Journal of the American Oil Chemists' Society 2021; 98: 163-172. doi: 10.1002/aocs.12456

20. Zuleta EC, Rios LA, Benjumea PN. Oxidative stability and cold flow behavior of palm, sacha-inchi, jatropha and castor oil biodiesel blends. Fuel Processing Technology 2012; 102: 96-101. doi: 10.1016/j.fuproc.2012.04.018

21. Soriano NU, Migo VP, Sato K, Matsumura M. Crystallization behavior of neat biodiesel and biodiesel treated with ozonized vegetable oil. European Journal Lipid Science and Technology 2015; 107: 689-696. doi: 10.1002/ejlt.200501162 


\section{LIU et al. / Turk J Chem}

22. Zhang J, Wu C, Li W, Wang Y, Han Z. Study on performance mechanism of pour point depressants with differential scanning calorimeter and X-ray diffraction methods. Fuel 2003; 82: 1419-1426. doi: 10.1016/S0016-2361(03)00028-0

23. Chen F, Liu J, Yang T, Yin S, Su M et al. Influence of maleic anhydride-co-methyl benzyl acrylate copolymers modified with long-chain fatty amine and long-chain fatty alcohol on the cold flow properties of diesel fuel. Fuel 2020; 268: 117392. doi: 10.1016/j.fuel.2020.117392

24. Mohanan A, Darling B, Bouzidi L, Narine SS. Mitigating crystallization of saturated FAMES (fatty acid methyl esters) in biodiesel. 3. The binary phase behavior of 1, 3-dioleoyl- 2-palmitoyl glycerolsters) in biodiesel. Multi length scale structural elucidation of mechanism responsible for inhibiting FAME crystallization. Energy 2015; 86: 500-513. doi: 10.1016/j.energy.2015.04.011

25. Holder GA, Winkler J. Crystal-growth poisoning of $n$-paraffin wax by polymeric additives and its relevance to polymer crystallization mechanisms. Nature 1965; 207: 719-721. doi: 10.1038/207719a0 